\title{
Una visión panorámica de las epidemias a través del tiempo
}

\section{A panoramic view of the epidemics through time}

\author{
Dr. Rolando Neri-Vela,* Acad. Dr. Raúl Carrillo-Esper,* \\ Dra. Luisa García-Rojas-Vázquez ${ }^{\ddagger}$
}

\begin{abstract}
RESUMEN. Desde la aparición del hombre en la tierra, las epidemias han impactado en la historia de la humanidad. En diciembre del año 2019, en Wuhan, China, apareció un nuevo virus, el SARS-CoV-2, que infectó a los seres humanos. La enfermedad secundaria a éste se denominó COVID-19 y rápidamente se diseminó a todo el mundo. Fue declarada pandemia el 11 de marzo del 2020. El objetivo de este trabajo es analizar en una línea de tiempo las principales epidemias que han azotado a la humanidad.
\end{abstract}

ABSTRACT. Since the appearence of man on earth epidemias have affected human history. This is a true today as it ever. In december 2019, in Wuhan, China, a novel coronavirus, SARS-CoV-2 appearing in human beings. The disease it has been named COVID-19. This new disease spreads quckly in the world, and it was declared a pandemic on march 11, 2020. The aim of this paper is to analize in a time line the main epidemics that have plagued humanity.

L as epidemias han sido grandes plagas que han acompañado al hombre a través de la historia. Desde el inicio de la edad antigua hasta el siglo XIX, gracias a los trabajos de Louis Pasteur, se terminó con la creencia de que las enfermedades eran producidas por castigos divinos o causadas por los malos olores, y se pasó a la teoría microbiana de la enfermedad. Sin embargo, estas enfermedades, aun en la actualidad, han causado muerte y pavor entre la población.

En la Historia de la Guerra del Peloponeso, Tucídides nos informa de una epidemia que se inició en Atenas durante el segundo año de esta batalla, causando una mortalidad espantosa en la población ática hacinada en las barracas situadas entre las Murallas Largas. En aquellos tiempos se pensaba que esas enfermedades se debían al enojo de Apolo por algún crimen cometido por los hombres en su ámbito religioso, como ya lo había expresado Homero en La Ilíada ${ }^{(1)}$. Tucídides narra que la epidemia empezó en Etiopía, entró en Egipto y en Libia, y llegó de allí a Atenas con los barcos que entraban en el puerto del Pireo. Refiere que, a pesar de las procesiones impetratorias y preguntas a los oráculos, murieron hombres piadosos e impíos, justos y soberbios, ricos y pobres por igual. Describe el origen del padecimiento en el vientre, su progresiva difusión por todo el cuerpo, la fiebre que provocaba una sed implacable, su duración y el momento de la crisis, lo poco frecuentes que eran las recaídas, los efectos de la enfermedad en los animales, especialmente en los perros y en las aves, así como las perturbaciones psíquicas producidas por la enfermedad, como la llamada ceguera psíquica, con la que muchos pacientes no se reconocían a sí mismos ni a sus parientes, aunque físicamente veían de modo correcto; o el general desánimo que favoreció el efecto de la enfermedad por falta de capacidad anímica de resistencia; y la terrible desmoralización de los hombres, que no vacilaban ya ante ningún crimen y sólo deseaban gozar del instante, puesto que la vida podía terminar en el momento siguiente.

Además, nos dice que los médicos no acertaban el remedio, ya que al principio desconocían la enfermedad, y muchos de ellos morían al visitar a los enfermos.

\section{Revista Mexicana de \\ Anestesiología \\ Octubre-Diciembre 2020 \\ Vol. 43. No. 4. pp 329-332}

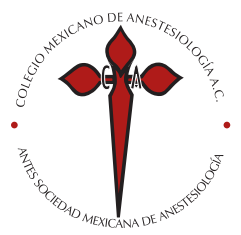

Palabras clave: Pandemia, SARS-CoV-2, COVID-19.

Keywords: Pandemia, SARS-CoV-2, COVID-19.

\footnotetext{
* Academia Nacional de Medicina. ‡ Facultad de Ciencias Médicas y Biológicas «Dr. Ignacio Chávez». Universidad Michoacana de San Nicolás de Hidalgo.

Solicitud de sobretiros: Dr. Rolando Neri-Vela Tuxpan Núm. 16-401, Col. Roma Sur, CDMX, 06760 México.

E-mail: drnerivela@hotmail.com
}

Recibido para publicación: 13-05-2020

Aceptado para publicación: 15-06-2020 
En su obra podemos leer:

«Los enfermos primero sentían un fuerte y excesivo calor en la cabeza; los ojos se les ponían colorados e hinchados; la lengua y la garganta sanguinolentas, y el aliento hediondo y difícil de salir, produciendo continuo estornudar; la voz se enronquecía, y descendiendo el mal al pecho, producía gran tos que causaba un dolor muy agudo; y cuando la materia venía a las partes del corazón, provocaba un vómito de cólera, que los médicos llamaban apocatarsis, por el cual con un dolor vehemente lanzaban por la boca humores hediondos y amargos; seguía en algunos un sollozo vano, produciéndoles un pasmo que se les pasaba pronto a unos, y a otros les duraba más. El cuerpo por fuera no estaba muy caliente ni amarillo, y la piel poníase como rubia y cárdena, llena de pústulas pequeñas; por dentro sentían tan gran calor, que no podían sufrir un lienzo encima de la carne, estando desnudos y descubiertos. El mayor alivio era meterse en agua fría, de manera que muchos que no tenían guardas, se lanzaban dentro de los pozos, forzados por el calor y la sed, aunque tanto les aprovechaba beber mucho como poco. Sin reposo en sus miembros, no podían dormir, y aunque el mal se agravase, no enflaquecía mucho el cuerpo, antes resistían a la dolencia, más que se puede pensar. Algunos morían de aquel gran calor, que les abrasaba las entrañas a los siete días, y otros dentro de los nueve conservaban alguna fuerza y vigor. Si pasaban de este término, descendía el mal al vientre, causándoles flujo con dolor continuo, muriendo muchos de extenuación».

«Esta infección se engendraba primeramente en la cabeza, y después discurría por todo el cuerpo. La vehemencia de la enfermedad se mostraba, en los que curaban, en las partes extremas del cuerpo, porque descendía hasta las partes vergonzosas y a los pies y las manos. Algunos los perdían; otros perdían los ojos, y otros, cuando les dejaba el mal, habían perdido la memoria de todas las cosas, y no conocían a sus deudos ni a sí mismos. En conclusión, este mal afectaba a todas las partes del cuerpo; era más grande de lo que decirse puede, $\mathrm{y}$ más doloroso de lo que las fuerzas humanas podían sufrir. Que esta epidemia fuese más extraña que todas las acostumbradas, lo acredita que las aves y las fieras que suelen comer carne humana no tocaban a los muertos, aunque quedaban infinidad sin sepultura; y si algunas los tocaban, morían» ${ }^{(2)}$.

Este episodio de la humanidad ha pasado a la historia con el nombre de plaga o peste de Atenas, y hasta la fecha no se ha podido dilucidar qué padecimiento fue, por lo que habrá que esperar a que la paleomicrobiología resuelva el misterio.

Otra de las grandes enfermedades que ha sufrido el hombre es la lepra, también conocida en su momento como «Mal de San Lázaro», por lo que los nosocomios encargados de su cuidado pasaron a llamarse «lazaretos». Las personas afectadas de lepra eran separadas de su comunidad, sus bienes requisados y quemados. Una vez en la leprosería, eran vestidos con ropas que los caracterizaban como tales, y no podían acercarse a las fuentes de agua que abastecían a las poblaciones. Se les proporcionaba una especie de matraca o una campana, que debían hacer sonar para que la gente sana que los escuchara no se les acercara (Figura 1), y se les ministraban alimentos y bebida que eran depositados en un lugar señalado ex profeso.

Ya en el Levítico se habla sobre la lepra y de algunas afecciones de la piel; pero la lista de estas enfermedades no tiene nada de científico, pues la misma palabra lepra (sara'at) designa tanto a la enfermedad humana como la lepra de los vestidos y de las casas. En este mismo texto se señala una receta mágica destinada a los sacerdotes para la curación o «purificación» de los leprosos ${ }^{(3)}$. Asimismo, en la ciencia hebraica medieval había leyes referentes a la lepra, plasmadas en el Levítico ${ }^{(4)}$.

En la China medieval el Tratado general de la causa y de los síntomas de las enfermedades, de Tch'ao Yuen-Fang, aparecido en 610 , contiene las primeras descripciones concretas de la viruela, el sarampión, la peste bubónica y la disentería ${ }^{(5)}$.

Giovanni Villani nos informa en su Crónica Florentina de una pestilencia que aconteció en el año 1347 y perduró hasta noviembre del año siguiente, que creció desde Florencia hasta llegar a Turquía y Grecia. Primero cercó todo el Levante, Mesopotamia, Siria, Caldea, Chipre, Creta, Rodas y todas las islas del archipiélago de Grecia, luego descendió a Sicilia y a Cerdeña, Córcega y a la isla de Elba. Menciona que era una enfermedad en que el hombre no yacía sino tres días; aparecían en la ingle o bajo las axilas bubones o glandulillas, que algunos les decían chichones, y de ellas manaba sangre, y a menudo esa enfermedad y la pestilencia se contagiaba al sacerdote que confesaba al doliente $\mathrm{o}$ a los que lo cuidaban, afectando principalmente a mujeres y a niños, en general gente pobre, muriendo en ese tiempo alrededor de 4,000 personas, en proporción de uno sobre veinte ${ }^{(6)}$.

Años antes se había presentado la pandemia de Justiniano, procedente del actual Yemen, invadiendo Egipto y expandiéndose por Europa y Asia Menor en el 541 d.C., hecho que se repitió en $1057^{(7)}$.

La lepra empezó a retroceder a principios del siglo XIV, y doscientos años más tarde ya casi no será en el Occidente cristiano más que un recuerdo de pesadilla. En 1348 cae sobre Europa la «gran peste negra», la peste bubónica transmitida por la pulga y la rata, con su terrible variante pulmonar (contagiosa de hombre a hombre) en las poblaciones sometidas a subalimentación y a clima húmedo. Debido a esta peste aparece la trentina en Ragusa (Duvrovnik) en 1377 y la cuarentena, que se impuso en Marsella en $1383^{(8)}$.

La peste es una enfermedad producida por Yersinia pestis, que fue aislado en 1894. El padecimiento comienza tras un período de incubación silenciosa, con fiebre elevada, acompañada de escalofríos, náuseas, sed y sensación de agotamiento y angustia. Tras este inicio, brusco e inespecífico, la enfermedad no sigue un cuadro clínico idéntico, sino que se presenta bajo 


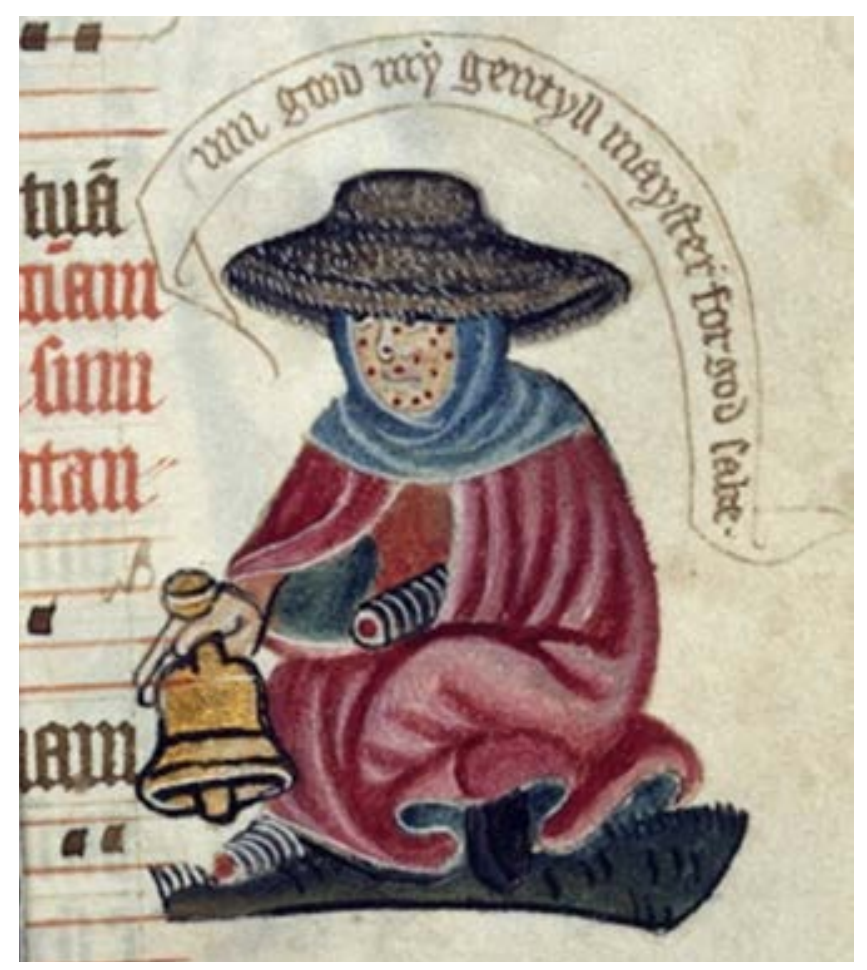

Figura 1: Leproso. British Library.

tres formas inconfundibles. La primera, la más clásica, es la bubónica. En la ingle, la axila o el cuello aparece el bubón, abultamiento doloroso y muy evidente de un ganglio. La segunda forma, la pulmonar, es de sintomatología menos florida, atestigua una infección directa del aparato respiratorio por inhalar partículas con el bacilo. De inicio también repentino, se acompaña de fiebre alta, ahogo, tos y esputos sanguinolentos. La forma septicémica se produce por la diseminación del bacilo desde los bubones ganglionares o el pulmón. Durante la septicemia se aprecian hemorragias cutáneas por todo el cuerpo con grandes placas de extravasación que con su color negro azulado, contribuyen al conocimiento del morbo como peste negra o muerte negra ${ }^{(9)}$.

En 1348, la epidemia alcanzó una propagación incontenible en gran parte de Italia, Francia y territorios de la Corona de Aragón. A fines de ese año y a lo largo del siguiente se extendió a Inglaterra y Gales y en los últimos meses de 1349 el mal penetró en Escocia.

En 1350, la plaga sacudió con fuerza a los reinos ibéricos occidentales. El autor de la Crónica de Alfonso Onceno hablará para ese año de la Mortandad grande.

Hasta 1352 aproximadamente, el valle del Danubio y las ciudades de la Hansa Teutónica transmitieron la peste hacia el norte y el este, por lo que entre 1347 y 1352 toda Europa y el Próximo Oriente se vieron en mayor o menor grado afectados por ella ${ }^{(10)}$.
En cuanto a la viruela, enfermedad producida por el Variola virus y conocida desde el Antiguo Egipto, fue identificada por Heródoto, subrayando su carácter epidémico, y hacia 1174, en China, el Suplemento sobre las fiebres, de Ku Yong, distingue la viruela, la varicela, el sarampión y la rubéola.

Los chinos practicaron la inmunización en contra de la viruela, pulverizando granos producidos por ésta, y según la doctrina del yin y el yang, si el paciente era niño, con ayuda de un popote de bambú aspiraba el polvo con la narina derecha, y si era niña, con la narina izquierda.

Más tarde se introdujo en el imperio otomano la inmunización llamada Método turco, en que la pulverización se introducía en el antebrazo, método popularizado por madame Montagu.

La viruela siguió causando muchos daños en la humanidad, y fue hasta 1796 que Edward Jenner, de Gloucester, introdujo la variolización. Una vez que Carlos IV, rey de España, se enteró de este hecho y encargó a Francisco Xavier Balmis que llevara este bien a todos sus súbditos de América y Filipinas.

En octubre de 1977, en Somalia, se registró el último caso de viruela en el mundo, y en 1980 la Organización Mundial de la Salud certificó la erradicación de la enfermedad, mal que hasta la fecha, afortunadamente, no se ha repetido.

En cuanto al cólera, o enfermedad del Ganges, surgió en forma epidémica en la India en 1817, en donde era un padecimiento endémico. Procedente de Rusia, llegó a Prusia oriental y de allí se propagó a Berlín, Lübeck y Hamburgo. En 1832 penetró en Francia, los Países Bajos y Gran Bretaña. En 1835 el padecimiento llegó a Italia y desde allí, a través del Tirol, a Baviera.

Sin síntomas previos, incluso una persona sana podía morir en el lapso de unas horas. Corren rumores por Europa de que el cólera es consecuencia de un envenenamiento planeado por los extranjeros.

En Alemania, en 1831, se recomienda una dieta sana y seca que debía contener, entre otras cosas, salchichas, carne de cerdo, chucrut, patatas y todo lo que ayudara a cargar el vientre, para poder evitar la epidemia.

Un papel especial lo constituían los baños de vapor, las camas húmedas y los dispositivos para ahumar. El homeópata Hahnemann recomendaba el alcanfor.

También se utilizaron bolos de artemisa, hierro candente o agua hirviendo sobre el vientre, sangrías, laxantes, eméticos, azotes con ortigas y baños fríos por inmersión rápida ${ }^{(11)}$.

En 1833, el cólera entró en México, y el 27 de junio de ese año se notifica el primer caso en la ciudad de Saltillo ${ }^{(12)}$.

En 1883, Robert Koch descubrió el germen causante del cólera, Vibrio cholerae.

Otra gran pandemia que afectó a la humanidad fue la llamada Gripe Española o Spanish Lady, pues España, al ser neutral en la Primera Guerra Mundial, notificó su presencia. Se caracterizó por fiebre elevada, dolor de oídos, cansancio extremo, diarreas y vómitos ocasionales, y la mayoría de las 
personas que fallecieron tuvieron una neumonía bacteriana secundaria. El primer brote se detectó el 04 de marzo de 1918 en un campamento del ejército de Estados Unidos en Funston, Kansas, y viajó hasta Francia con el contingente militar estadounidense destinado a combatir en la Gran Guerra. El $1^{\circ}$ de abril apareció en el país galo contaminando a la población civil y a todas las fuerzas contendientes. Un mes más tarde estaba activa en regiones como España, Portugal, Italia, Grecia, Albania, Escocia, el norte de África y los Balcanes.

La segunda oleada epidémica salió de las ciudades de Brest (Francia), Boston (Estados Unidos de América) y Freetown (Sierra Leona) durante agosto de 1918. A finales de febrero de 1919 estaba invadida gran parte del planeta, cesando a finales de diciembre. El tercer y último brote localizado en Europa y Norteamérica surgió a principios de 1919 y se extinguió en marzo siguiente, castigando dentro de Europa con mayor rigor a España e Italia.

En esta epidemia se estima que el grado de afectación alcanzó un rango entre 400 y 600 de cada mil habitantes y provocó al menos cien millones de óbitos, especialmente entre los menores de cinco años, varones jóvenes (de 20 a 40 años de edad), mayores de 60 años y mujeres, provocando serios daños en la economía.

El virus causante de la gripe española fue el AH1N1 1918, de la familia Orthomyxovirus ${ }^{(13)}$.

Hacia 1957 hubo otra epidemia, conocida como Gripe Asiática, que se debió al virus H2N2, y en 1968 se presentó la Gripe de Hong Kong, debida al virus H3N2.
Otro de los problemas de salud pública emergió en la década de los 80 del siglo XX, con la presencia del virus de la inmunodeficiencia humana, el que ha sido en parte controlado en cuanto a sus complicaciones y a la muerte que conllevan a partir de 1996, con la aparición de la terapia antirretroviral. Sin embargo, el SIDA aún persiste.

El ser humano ha padecido otros males, como la sífilis, la fiebre amarilla, el Ébola, entre otras más.

En abril de 2009, en California y Texas, en los Estados Unidos de América, y en los estados de Oaxaca y Veracruz, en México, se observaron los primeros casos de pacientes hospitalizados con infecciones respiratorias graves y alta letalidad, lo que alertó a las autoridades sanitarias para identificar la causa, y fue hasta finales de abril que se emitieron informes acerca de un nuevo virus de influenza AH1N1, por lo que más adelante la Organización Mundial de la Salud elevó ese aviso a nivel 5 de pandemia, pues se detectaron casos en todo el mundo ${ }^{(14)}$.

En 2003 apareció el SARS y a fines de 2019 el COVID-19.

Desde la Edad Media el personal médico ha muerto atendiendo a sus pacientes, como lo es en la actualidad.

Algunos expertos han advertido que la mitad de la población mundial estará infectada por el COVID-19 al final de este año ${ }^{(15)}$.

Lo cierto es que algunos gobiernos han actuado con tibieza ante la pandemia de COVID-19, o han ignorado su potencial letalidad, exponiendo a la población a sus efectos, ayudado esto, en gran parte, por la pobreza e ignorancia de la gente.

\section{REFERENCIAS}

1. Homero. La Ilíada. "Sepan cuántos...” Núm. 2. México: Editorial Porrúa, S.A.; 1975. pp. 1-8.

2. Tucídides. Historia de la guerra del Peloponeso. Barcelona: Ediciones Orbis, S.A.; 1986. pp. 117-120.

3. Taton R. Historia general de las ciencias. Volumen 1. Barcelona: Editorial Orbis, S.A.; 1988. pp. 165-166.

4. Taton R. Historia general de las ciencias. Volumen 1. Barcelona: Editorial Orbis, S.A.; 1988. p. 616.

5. Taton R. Historia general de las ciencias. Volumen 3. Barcelona: Editorial Orbis, S.A.; 1988. p. 579.

6. Villani G. Crónica florentina. Colección: Historia medieval. Buenos Aires: Editorial Tekné; 1984. pp. 137-140.

7. Sánchez FL, Neri VR. Las enfermedades epidémicas de Asturias. De la peste de 1598/1602 a la gripe de 1918/1919. Ilustre Colegio Oficial de Médicos de Asturias, Oviedo. 2019. p. 31.

8. Taton R. Historia general de las ciencias. Volumen 3. Barcelona: Editorial Orbis, S.A.; 1988. pp. 695-696.
9. Carreras A, Mitre E, Valdeón J. La peste negra. Madrid: Cuadernos historia 16, núm. 17; 1985. pp. 6-7.

10. Carreras A, Mitre E, Valdeón J. La peste negra. Madrid: Cuadernos historia 16, núm. 17; 1985. p. 12.

11. Crónica de la medicina. $4^{\mathrm{a}}$ edición. México: Senosiain; 2008. pp. 272273.

12. Neri VR. Historia del cólera en México, II. Ovaciones/La Segunda... México, D.F.: 21 de mayo de 1993. p. 7.

13. Sánchez FL, Neri V. Las enfermedades epidémicas de Asturias. De la peste de 1598/1602 a la gripe de 1918/1919. Ilustre Colegio Oficial de Médicos de Asturias, Oviedo. 2019. pp. 155-157.

14. Frías-Salcedo JA. Crónicas de la epidemia de influenza A H1N1 en México. 2009-2010. Relato de lo aprendido... Rev Sanid Milit Mex. 2010;64:280-286.

15. Jones DS. History in a crisis - Lessons for COVID-19. N Engl J Med. 2020;382:1681-1683. 